Zwijsen, S.A., Depla, M.F.I.A., Niemeijer, A.R., Francke, A.L., Hertogh, C.M.P.M. Surveillance technology: an alternative to physical restraints? A qualitative study among professionals working in nursing homes for people with dementia. International Journal of Nursing Studies: 2012, 49(2), 212-219

\begin{tabular}{|l|l|}
\hline Postprint Version & 1.0 \\
\hline Journal website & $\underline{\text { http://www.sciencedirect.com/science/article/pii/S0020748911003567 }}$ \\
\hline Pubmed link & $\underline{\text { http://www.ncbi.nlm.nih.gov/pubmed/21962335 }}$ \\
\hline DOI & $10.1016 /$ j.ijnurstu.2011.09.002 \\
\hline
\end{tabular}

This is a NIVEL certified Post Print, more info at http://www.nivel.eu

\title{
Surveillance technology: An alternative to physical restraints? A qualitative study among professionals working in nursing homes for people with dementia
}

\author{
SANDRA A. ZWIJSEN ${ }^{\mathrm{A}}$, MARJA F.I.A. DePlaA ${ }^{\mathrm{A}}$, ALISTAIR R. NIEMEIJER ${ }^{\mathrm{A}}$, ANNEKE L. FRANCKE, ${ }^{\mathrm{B}, \mathrm{C}}$, CEES \\ M.P.M. HERTOGH ${ }^{\mathrm{A}}$ \\ ${ }^{a}$ Department of Nursing Home Medicine, EMGO+ Institute for Health and Care Research, VU Medical \\ Center, Amsterdam, The Netherlands \\ ${ }^{b}$ NIVEL, Netherlands Institute for Health Services Research, Utrecht, The Netherlands \\ ${ }^{c}$ Department of Public and Occupational Health, EMGO+ Institute for Health and Care Research, VU \\ Medical Center, Amsterdam, The Netherlands
}

\begin{abstract}
Background: Working with surveillance technology as an alternative to traditional restraints creates obvious differences in the way care is organised. It is not clear whether professional caregivers find working with surveillance technology useful and workable and whether surveillance technology is indeed used to diminish restraint use.

Objectives: The aim of this study was to obtain an insight into the view of Dutch dementia care professionals on the feasibility of surveillance technology as an alternative to physical restraints.

Design: Qualitative study.

Setting: The study was carried out in seven nursing homes for people with dementia in The Netherlands.

Participants and methods: Semi-structured interviews were held with nine key persons from seven nursing homes for people with dementia. Also, six focus group discussions were held with groups of nurses and two focus group discussions were held with multidisciplinary teams.

Results: The dementia care professionals named three different ways in which surveillance technology can be used: to provide safety in general, to provide additional safety, and to provide more freedom for the residents. In addition to this, the dementia care professionals mentioned four limitations in the use of surveillance technology: it is unable to prevent falling, it cannot guarantee quick help, it does not always work properly, and it could violate privacy.

Conclusion: Dementia care professionals consider surveillance technology supplemental to physical restraints, rather than as an alternative. Improvement of devices and education of care professionals might increase the support for using surveillance technology as an alternative to physical restraints.
\end{abstract}


Zwijsen, S.A., Depla, M.F.I.A., Niemeijer, A.R., Francke, A.L., Hertogh, C.M.P.M. Surveillance technology: an alternative to physical restraints? A qualitative study among professionals working in nursing homes for people with dementia. International Journal of Nursing Studies: 2012, 49(2), 212-219

\section{WHAT IS ALREADY KNOWN ABOUT THE TOPIC?}

- $\quad$ The use of physical restraints has various negative side effects, therefore the use of physical restraints should be diminished.

- $\quad$ Surveillance technology is advocated as an alternative for physical restraints use.

- Working with electronical devices (e.g. surveillance technology) creates differences in the way care for people with dementia is organised.

\section{WHAT THIS PAPER ADDS}

- Information about the view of care professionals on surveillance technology as an alternative to restraints.

- $\quad$ Practice based information about the way surveillance technology is currently being used in Dutch nursing homes.

- $\quad$ Practice based information about the pro's and cons of the use of surveillance technology as an alternative to restraint use in the nursing home care for people with dementia.

\section{INTRODUCTION}

Physical restraints, such as safety belts and bedrails, are used in nursing homes all over the world, with a prevalence somewhere between $41 \%$ and $66 \%$ (Hamers and Huizing, 2005). There is growing awareness that the use of these means has serious psychological and physical disadvantages, such as increased cognitive decline and decreased mobility and has even led to death in some cases (Evans et al., 2002). Physical restraints are most often used to prevent risky behaviour and risky situations, e.g. falling ( [Halfens et al., 2010] , [Hamers and Huizing, 2005] and [Karlsson et al., 2001] ). However, several studies have shown that reducing the use of physical restraints does not increase the incidents of residents falling and some authors even state that the number of serious injuries decreases when physical restraints are not used ( [Engberg et al., 2008] , [Evans et al., 2003] and [Neufeld et al., 1999] ). This makes the use of physical restraints questionable.

In most developed countries, the legislation regarding the use of physical restraints is based on, among other things, guidelines of the United Nations and the World Health Organization and the European Convention on Human Rights ( [Council of Europe, 1950] , [0055] and [World Health Organization, 2005] ). Nevertheless the content of the laws and the definition of central concepts in different countries varies (Legemaate et al., 2007). For example, in The Netherlands, where this study took place, the Special Admission to Psychiatric Hospitals Act (BOPZ) does not define the concept of freedom restriction of restraint, but instead uses the umbrella term 'fixation' to indicate which interventions are to be considered restrictive and are therefore only allowed under very strict conditions.

Both governments and practitioners in dementia care in many countries are developing policies to diminish the use of physical restraints. A diminution in the use of restraints could be achieved in several ways, for example through the use of staff education. Nevertheless, given that people with dementia living in nursing homes still have to be protected against risks, a substitution for physical restraints must also be found. However, Moore and Haralambous (2007) and de Veer et al. (2007) found that staff do not know much about alternative approaches to care. In the Moore and Haralambous study, family members of nursing home residents stated that they would possibly change their opinion about restraints if they knew that other safer and more effective interventions were available.

One of the available alternatives to the use of physical restraints might be the use of surveillance technology. There are a variety of surveillance technology devices that may be used in the nursing home. For example, sensors can be placed in the living room or bedroom that register noise, movement or absence of movement (Lauriks et al., 2008). In addition, continuous monitoring through the use of acoustic monitoring devices, cameras or global positioning systems can also be used. These monitoring devices do not restrict freedom of movement, and afford staff the opportunity to take action when situations appear to be dangerous. Furthermore, residents can wear a chip in their clothing that can give them access to certain parts of the building, while preventing them to going to other parts of the building (Lauriks et al., 2008). These devices can be individually tailored to the needs and capacities of residents, and may give residents more freedom of movement.

Surveillance technology is increasingly being implemented in the residential care for people with dementia as possibilities are becoming more well-known. In The Netherlands, the Health Care Inspectorate 
promotes the use of surveillance technology as a way to diminish the use of more severe means of restricting freedom. In 2009, already $91 \%$ of the nursing homes were using some kind of surveillance technology in the care for people with dementia (Health Inspectorate, 2009). Nevertheless, the forthcoming new law on the use of restraints still considers surveillance technology as a form of restraint (which can substitute more severe forms of restraints such as fixation), as is already the case in some other European countries like Scotland (Patrick, 2008). Working with surveillance technology creates obvious differences in the way care is organised. For example, nurses have to react to alarms which might change or even take away their daily routine. Furthermore, when residents are wearing a chip, the way nurses monitor residents changes from residents being in one place to residents walking around the whole nursing home. However, it is not clear whether nurses find working with surveillance technology useful and workable and whether surveillance technology is indeed used to diminish restraint use. Therefore, the aim of this paper was to examine the views of professionals in dementia care on the use of surveillance technology as an alternative to physical restraints. How is surveillance technology currently being used in Dutch nursing homes? What are, according to the professionals, the pro's and cons of using surveillance technology in nursing home care? To answer these questions, we interviewed both nurses and nurse assistants, as well as key persons involved in the implementation of restraints and surveillance technology policy.

\section{METHODS}

\subsection{Design}

A qualitative approach was chosen, consisting of semi-structured interviews and focus groups. Such an approach is particularly useful for understanding meanings and experiences and for unpacking complex issues in health care, like views and feelings regarding restraint use ( [Mays and Pope, 2000] and [Pope et al., 2002] ). Interviews can reveal issues or concerns that have not been anticipated or considered by the researchers (Pope et al., 2002), while the value of focus groups specifically resides in generating data about a complex issue through the interaction of participants. Group members can talk to each other and discuss and ask questions, which is useful for finding out about shared experiences ( [Bloor et al., 2001] and [Pope et al., 2002] ). Inductive thematic analysis was used to interpret the data, which is a method for finding patterns and trends in qualitative data. Because this method of analysis has the advantage of theoretical freedom it is a flexible and useful research tool, that offers a rich and detailed, yet complex interpretation of data (Braun and Clarke, 2011). Inductive analysis means there were no pre-supposed themes; e.g. all themes emerged from the data.

\subsection{Participants}

In The Netherlands, nursing home care for people with dementia is organised in dementia special care units. We interviewed care professionals working in these units in three nursing homes for people with dementia with an active policy to implement and use surveillance technology and four nursing homes not pursuing this policy. We purposely selected both kinds of nursing homes because we suspected that perspectives on surveillance technology might differ depending on whether or not an active policy on surveillance technology was pursued in a nursing home. Although such technology was used in both types of nursing homes, the nursing homes with an active surveillance technology policy had more devices with a broader variety of application options available than the homes with no such policy. Whether or not nursing homes had an active policy on surveillance technology was known from a previous national survey undertaking by our research group on ethics and technology in residential care. The following devices were used in the nursing homes: acoustic monitoring, chips worn in clothing, inactivity sensors, movement sensors, door sensors, bed pressure sensors (for an overview, see Table 1).

\section{[TABLE 1]}

\subsection{Individual interviews}

Individual semi-structured interviews were held with nine key persons in the nursing homes. Key persons in this study were defined as professionals (e.g. managers, physicians) within the nursing home taking a lead in the development, implementation and enforcement of policies regarding the use of physical restraints and alternatives for restraints, such as the use of surveillance technology. We asked the management in each nursing home to introduce the interviewer to the person who fitted this description. In 
Zwijsen, S.A., Depla, M.F.I.A., Niemeijer, A.R., Francke, A.L., Hertogh, C.M.P.M. Surveillance technology: an alternative to physical restraints? A qualitative study among professionals working in nursing homes for people with dementia. International Journal of Nursing Studies: 2012, 49(2), 212-219

most nursing homes, one person could be described as key person. However, in two nursing homes it was necessary to interview two key persons to get a complete picture. The interviews were conducted by the first author, using a topic list which was based on earlier research of Lauriks et al. (2008).

\subsection{Focus groups}

Eight focus group discussions were held in the nursing homes. The focus groups were held in every participating nursing home, in one of the homes we conducted both a focus group discussion with nurses and one with members of the multidisciplinary team. The first author conducted all focus groups and was assisted by one of the other researchers. The professionals participating in the focus group discussions were either registered nurses and certified nurse assistants (both further referred to as nurses) or other members of a multidisciplinary team. The selection of participants for the focus group discussions was made by the contact person, usually a team leader or manager, within the nursing home. The first author instructed them to select 6-8 participants with different backgrounds with regard to the ward they work on, the shifts they are working (e.g. night or day), their working experience and education level. In the six focus groups where the professionals were exclusively nurses, a mix of nurses with different educational levels (registered nurses, certified nurse assistants, student nurses), work experience and shifts were represented. The number of professionals in these focus groups ranged from four to eight. The two multidisciplinary focus group discussions, containing five or six professionals, were held with professionals who were usually involved in cases regarding restraint use. A physician, psychologist and a nurse participated in both of the multidisciplinary focus groups, the other professionals involved in cases regarding restraints differed for both groups. The focus group discussions were initiated through the use of one or more vignettes (Fig. 1). Vignettes are descriptions of cases or scenarios with particular characteristics which makes them suggestive of real life situations to participants. They are often used in surveys and qualitative interviews (Bloor et al., 2001). Prior to the focus group discussion, the contact persons were asked to provide information about one or more cases in their nursing home which they had found to be complex with regard to decisions on using restraint or surveillance technology. This case then was used to make the vignette. The discussion was then started with questions about the cases on the vignette. We chose to use vignettes instead of a focus question as a start of the group discussions to enhance the validation of the data and to avoid social desirable answers. Each focus group discussion took approximately 1 hour.

All interviews and focus groups were recorded and fully transcribed. The data collecting process ran from March 2009 to February 2010.

\subsection{Analysis}

\section{[FIGURE 1]}

The transcripts were initially coded using open codes based on the words the participants used, which contributes to the trustworthiness of the study. The coding process was supported by ATLAS.Ti (2008). To ensure external validation and increase reliability, two researchers independently coded the data, and then compared and discussed their codes. Differences were discussed until consensus was reached. Second, three researchers wrote memos about the main topics in the data, which were compared and discussed. When patterns and trends were identified, cases which appeared to contrast with these trends were examined closely (Whitehead, 2004). Data were examined by the first author for consistency and variance between the themes. The entire process of analysis was accompanied by feedback and discussion with the other authors. Finally, data saturation was evident in both the interviews and the focus group discussion.

\section{ETHICAL APPROVAL}

All data was anonymised. Informed consent was asked from all participants. The study protocol was approved by the Medical Ethics Review Committee of the VU University Medical Center.

\section{RESULTS}

Analysis of the data resulted in two main themes as well as several subthemes. The main themes were 'uses of surveillance technology' and 'limitations of surveillance technology'. The subthemes within the main theme 'uses of surveillance technology' were:

- $\quad$ Providing safety in general 
Zwijsen, S.A., Depla, M.F.I.A., Niemeijer, A.R., Francke, A.L., Hertogh, C.M.P.M. Surveillance technology: an alternative to physical restraints? A qualitative study among professionals working in nursing homes for people with dementia. International Journal of Nursing Studies: 2012, 49(2), 212-219

- $\quad$ Providing additional safety

- $\quad$ Providing more freedom for residents

The subthemes within the main theme 'limitations of surveillance technology' were:

- $\quad$ Surveillance technology is not able to prevent falling

- $\quad$ Surveillance technology cannot guarantee quick help

- $\quad$ Surveillance technology devices do not always work properly

- $\quad$ Surveillance technology could violate privacy

These themes will be presented below with a description of the theme and quotes from the transcripts that are a clear illustration of that theme.

\section{USES OF SURVEILLANCE TECHNOLOGY}

\subsection{Providing safety in general}

Providing optimal safety was named as one of the fundamental functions of surveillance technology. Providing safety was therefore the main goal of using surveillance technology according to key figures and nurses without necessarily aiming at a reduction of physical restraints. The key persons interviewed stated that they use surveillance technology to provide optimal safety for the residents and therefore peace of mind for the nurses and relatives, as is shown in the quote below:

Key person (physician, nursing home \#1) regarding the reasons for using surveillance technology:

So, you want safety, you want to build that in as much as possible for the client, the family, as well as for the nursing staff to give them a sense, of well, 'we've got option of monitoring'. That's the idea behind it really.

\subsection{Providing additional safety}

Professionals stated that surveillance technology was often used supplementary to existing forms of restraints. The most commonly used combination of a traditional restraint and surveillance device was to place a sensor next to a bed with bedrails. This way, it was argued, the nurse will know when a resident climbs over a bed rail. According to the professionals, in the past residents who had climbed over a bed rail sometimes lay on the floor for a long period of time. The sensor therefore provides an extra safety, or at least a feeling of extra safety as reported by the professionals. Key persons stated that, because of this feeling of extra safety caused by surveillance technology, it is tempting to use surveillance technology devices on almost all residents. Nurses and key persons stated that they did not regard the use of surveillance technology as harmful in any way and that they felt they should be able to place surveillance technology devices whenever they felt it could give them or others more peace of mind about the safety of residents. Surveillance technology was regarded as a convenient supplement to the interventions already available, e.g. bed rails or belts.

Key person (physician, nursing home \#6) on bedrails:

What do you think, is she going to get over it? If we have any doubts, we put a sensor in immediately.

Key person (physician, nursing home \#7) on large scale use of sensors:

And that's why it's creeping in. Those things are always on, even when they're not needed. It's like a sense of security, "I know that he's laying in bed".

\subsection{Providing more freedom for residents}

One advantage of using surveillance technology the professionals mentioned is that they do not have to disturb the residents in their sleep or daily activities. In the past, caregivers repeatedly checked on the residents to make sure they were safe and comfortable. When the surveillance technology devices work properly, nurses can rely on the devices to tell them when to act. Surveillance technology may also give residents more freedom of movement. For instance, in the past the only way to prevent residents from wandering away was to lock the ward door. The use of chips in clothing means they can safely leave the ward because the chip prevents them from wandering away through the front door, as the following quote shows:

Key person (manager, nursing home \#2) on freedom caused by the chip:

That's a new development, because it enhances freedom of movement compared to before, because you simply couldn't get through the door. People are now able to walk independently to the smoking room. And then walk back. And you know they won't be able to get out, when they get back half an hour later.

Nurse (nursing home \#5) about acoustic monitoring: 
Zwijsen, S.A., Depla, M.F.I.A., Niemeijer, A.R., Francke, A.L., Hertogh, C.M.P.M. Surveillance technology: an alternative to physical restraints? A qualitative study among professionals working in nursing homes for people with dementia. International Journal of Nursing Studies: 2012, 49(2), 212-219

They can come out of bed if they want to. And than they can go into the living room. They can get something to eat or drink if they want to. Really, they have gained more freedom, I think.

\section{LIMITATIONS OF THE USE OF SURVEILLANCE TECHNOLOGY}

\subsection{Surveillance technology is not able to prevent falling}

Sensors were the most used surveillance technology device in the participating nursing homes. Several professionals complained that the sensors were not suitable in all unsafe care situations. The most mentioned problematic aspect of sensors is the fact that they can register, but not prevent falling. In some cases, an alarm is equal to a fall accident. The use of a sensor thus seems rather pointless in such cases, as is illustrated in the next quote:

Key person (physician, nursing home \#2) on the fact that a sensor is not always useful:

It's really those kinds of people who are still thinking "I want to get out". I know for sure that it wouldn't work for them (...) and also know that a laser wouldn't be sufficient: once they get out it's too late to pick them up again.

\subsection{Surveillance technology cannot guarantee quick help}

Although the use of surveillance technology can give a sense of safety, a quick response to an alarm is not guaranteed. One of the problems caregivers experienced with surveillance technology use was the amount of signals they received from the sensors. When a resident is restless or several residents trigger their sensor at the same time, caregivers simply do not have enough capacity to react to all signals. Some professionals however stated that it helps when staff know the residents well, because they then know which resident has the highest priority. The interview fragment below is illustrative for the problem with the amount of signals:

Night staff (focus group, nursing home \#1) about working with sensors:

But that's become apparent because I only work nights, if there are very unsettled people, then well, you can't really use it during nights, because you'd be going to them every minute, and that would be unworkable.

\subsection{Surveillance technology devices do not always work properly}

Some nurses complained about the functioning of the surveillance technology devices. First of all, the devices do not always work properly. Some break down easily or have to be sited very accurately to work. In some nursing homes, nurses even walk extra rounds to ensure that all devices are working correctly. Some professionals even stated that they felt they had to use restraints because of the use of surveillance technology. In one of the participating nursing homes a tag system was used. Every resident wore a personal tag that provided access to specific areas. In the past, nurses and visitors were the only ones who had a key or a code to pass locked doors. Problems arose because in this new situation it became easier for residents to come along with each other when a tag has opened a door. Caregivers felt forced to restrict the freedom of some residents in order to keep other residents save, as is shown in the second citation below.

Nurses (focus group, nursing home \#1) on the reliability of the sensors:

Primary caregiver 1: I always check whether the thing's (...) working during the first round.

Primary caregiver 2: as well as if they're positioned properly, because sometimes they're at an angle, that went wrong recently at our home. So the person fell out of bed and the night duty didn't notice.

Nurse (focus group, nursing home \#2) on additional limitation caused by surveillance technology:

Then there's this gentleman who's not allowed out the unit...And on the other side, opposite in fact, there's a lady. Who's constantly walking in and out the unit, and opening the door. So, the result is that the gentleman walks off (...) So the other unit came up with a different solution: they took the lady out of the wheelchair, and sit her for about 2 hours in an armchair [out of which she could not get up], just to give the unit opposite a break, so they don't have to keep coming backwards and forwards all the time. But I think that's a restriction on her movements as well.

\subsection{Surveillance technology could violate privacy}

Although in general professionals were not very reserved in using surveillance technology, we did interview professionals who had ethical objections to the large scale use of surveillance technology. Specifically in the nursing homes that did not use much surveillance technology. Caregivers stated that privacy is at stake when using surveillance technology devices, such as cameras and other monitoring 
Zwijsen, S.A., Depla, M.F.I.A., Niemeijer, A.R., Francke, A.L., Hertogh, C.M.P.M. Surveillance technology: an alternative to physical restraints? A qualitative study among professionals working in nursing homes for people with dementia. International Journal of Nursing Studies: 2012, 49(2), 212-219

devices. Also, some professionals in nursing homes that did use a lot of surveillance technology expressed ethical concerns about privacy, although this had not yet led to any action to rethink their surveillance technology use.

Key person (Physician nursing home \#4) on privacy and surveillance technology:

Well, you know, the ethical aspect sometimes strikes me...if you don't need it and someone's fast asleep in bed, then I think it's not really my business what he's doing or wants to in bed...I think that's on the boundaries of privacy whether it's ethically responsible in terms of someone's privacy.

\section{DISCUSSION}

The aim of this study was to examine nurses' and key persons' view on the use of surveillance technology as an alternative to physical restraints. We wanted to get insight into how surveillance technology is currently being used in Dutch nursing homes and what the pro's and cons of using surveillance technology are according to the professionals working in nursing homes. We included nursing homes at different stages of policy implementation on surveillance technology use.

The care professionals considered the use of surveillance technology as a way to provide optimal safety, with or without the supplemental use of physical restraints. According to the care professionals, using surveillance technology may give peace of mind for caregivers in a harmless way. Consequently, nurses and key persons are far less hesitant to use surveillance technology than they are on using traditional interventions, such as safety belts.

Next to providing safety, the use of surveillance technology can give residents more freedom according to the professionals. When nurses are able to rely on surveillance technology to tell them when they should check up on a resident, the nurses do not have to disturb them unnecessarily. Furthermore, through the use of chips, residents may have more freedom of movement because they can safely wander through the nursing home. It is important to note that the way surveillance technology is used according to the professionals is not limited to substituting physical restraints.

However, to benefit from the extra freedom that surveillance technology can offer, nurses must have faith in the accurate functioning of the devices and, in addition, they have to learn to trust the devices from a distance. Professionals in this study complained about vulnerability of the devices they worked with. Some devices are easily broken down, or they have to be placed very precisely to work properly. Other devices were found to be too sensitive and register signals also in situation where the resident is not in need of help. The concerns for residents' safety is one of the reasons for care professionals to support the belief in restraint use (Karlsson et al., 2000). If the devices cannot be trusted to ensure residents safety because they do not always work properly, this foundation for supporting the belief in restraint use will probably not diminish. In this study, nurses even stated they walk extra rounds to ensure the surveillance technology devices are working correctly. Another consequence of the inadequacy of the surveillance technology devices is that in some nursing homes, residents encounter more restraints because of the surveillance technology used for other residents. Walking extra rounds or using extra restraints is, of course, opposite to the intentions at the start of using surveillance technology.

Another perceived limitation of surveillance technology use concerned the fact that the technology can register events, but it cannot ensure the prevention of dangerous situations. First, there are residents who will fall down immediately when they try to get out of bed or out of their chair. Nurses can never be in time to prevent this when they have to react to a signal. In addition to this, when several surveillance technology devices give a signal, nurses cannot react to them all at the same time.

However, it should be noted that the use of traditional restraints, for example bedrails, can also not guarantee residents will not fall (Capezuti et al., 2007). Furthermore, research by Neufeld et al. (1999) shows that although more fall incidents may occur when surveillance technology replaces restraints, there are far less serious injuries than when restraints are used. Nevertheless, nurses in our study apparently feel more insecure about the safety of residents when surveillance technology is used than when restraints are used. However, policy in nursing homes ignores these feeling through prescribing the use of surveillance technology. In addition, in The Netherlands, the Health Inspectorate promotes the use of surveillance technology as an alternative to restraint use (Health Inspectorate, 2009).

When people have to act against their moral beliefs they may experience moral distress. Feelings of moral distress may have serious negative effects such as decreased self-esteem and loss of the ability to provide good patient care (Austin et al., 2005). Research has shown that nurses experience moral distress when 
using physical restraints because it contravenes with their moral beliefs (Weiner et al., 2003). In a recent paper on the current study we have also found this to be true (Zwijsen et al., 2011). However, when nurses have to use surveillance technology while they feel restraints are the safer option they are also acting against their moral beliefs. Indeed, nurses experienced moral distress in both the use of physical restraints and surveillance technology in this study (Zwijsen et al., 2011). It therefore seems important to take the sting out of this moral conflict that nurses experience. This can be done through altering the action nurses have to take or altering their moral beliefs. As research on reducing restraint use shows, the solution seems to lie in altering nurses' thoughts about restraints and alternatives to restraints ( [Chuang and Huang, 2007] and [Moore and Haralambous, 2007] ). Thus, in accordance with the result in this current paper, when implementing surveillance technology in nursing home care, a lot of attention should be given to educating and supporting nurses in this transition.

Some professionals were concerned about the violation of privacy when using surveillance technology. They feel privacy of residents could be at stake when residents are being continuously monitored. However, proponents of surveillance technology advocate that the use of monitoring increases privacy of residents because nurses do not have to walk rounds and check up on residents. Apart from the concerns regarding privacy, no other ethical objections to the use of surveillance technology were made. This finding is in contrast with a recent review on the ethical aspects of surveillance technology by Niemeijer et al. which names several moral problems with respect tot surveillance technology (Niemeijer et al., 2010). For instance, the use of surveillance technology could have an impact on the quality of the care relationship by reducing the moments of face to face contact: patients are cared from 'from a distance'. In addition, certain forms of technology such as tagging devices, might also cause a loss of dignity through stigmatisation. Although these concerns were not expressed by our participants, they must not be forgotten when implementing surveillance technology in daily care.

Some remarks have to be made with regard to the limitations of this study. First of all, not all interviewed people already had experience with working with the devices they were interviewed about. For example, the nurses in our study who expressed ethical concerns about possibly privacy violation through the use of surveillance technology all worked in nursing homes where surveillance technology was not broadly available and most of them did not have objections to using sensors, which were available in all of the nursing homes. Accordingly, being unfamiliar with surveillance technology devices may possibly cause some of the ethical concerns among nurses. Apart from the differences in concerns about privacy, we did not found any differences between the results from the different nursing homes. The key persons who felt that privacy was violated worked in both types of nursing homes. A review by Niemeijer et al. (2010) has already shown that both scholars and people with dementia have expressed concerns regarding the privacy violating qualities of surveillance technology, yet a total lack of concern for privacy was found in a survey among nurses themselves. Landau et al. (2010) has argued that the trade-off between the need for privacy and the right to autonomy and privacy is influenced by the locus of responsibility for the safety of people with dementia. The people who feel responsible value the need for safety more, while the right to autonomy and privacy is valued more by the people who do not feel direct responsibility. This could explain our findings, since the caregivers most likely feel more direct responsibility for the residents they care for than the key persons, who are more responsible for the overall policy in the nursing home.

A second limitation of this study could be that although in some cases the device (e.g. sensor, camera) were specified, all kinds of different devices were discussed under the umbrella term 'surveillance technology', which makes it unclear whether it is legitimate to use these results on discussing specific separate devices. It would, however, be interesting to do further research on more specific devices to see whether views on the use of specific devices differ from each other. Also, research in other countries than The Netherlands needs to be done to ensure these results are applicable beyond the Dutch situation.

Finally, the selection of participants for interviews and focus groups was done by the contact person from the nursing homes themselves. This might have introduced bias in the selection of participants. However, as discussed earlier, the participants seemed very open to discuss both positive as negative feelings and experiences. Still, in further research it would be interesting to use participating observational methods to get insight in the use of surveillance technology in nursing homes. Because of the direct way of observation this methods has high external validity in unravelling what really happens in the daily practice of using (Pope et al., 2002). 
Zwijsen, S.A., Depla, M.F.I.A., Niemeijer, A.R., Francke, A.L., Hertogh, C.M.P.M. Surveillance technology: an alternative to physical restraints? A qualitative study among professionals working in nursing homes for people with dementia. International Journal of Nursing Studies: 2012, 49(2), 212-219

\section{CONCLUSION}

Surveillance technology was not seen as a satisfactory alternative to traditional restraints in all regards. There are different causes that might explain this finding. Surveillance technology was mostly used in an unspecified and ill-considered way and it was viewed supplementary to existing measures rather than as a substitution, in both nursing homes with and without an active policy on surveillance technology. The fact that the devices do not always work properly is one of the reasons why surveillance technology is not an adequate alternative to using restraints at this moment. Improvement and more sophisticated devices could solve this problem. Next to this, surveillance technology is currently being implemented without notion for the moral beliefs of nurses, who are foremost concerned about safety and the reliability of devices. Education, focusing on the risks of restraints and encouraging a change of attitude of care professionals regarding (alternatives to) restraints seems essential to increase the support for using alternatives to restraints. A limitation mentioned of surveillance technology that is much more difficult to solve lies in the principle of monitoring devices itself: they monitor the resident, but they do not prevent dangerous situations. Finally we found that surveillance technology was used more widely than just as a substitution for physical restraints. It seems that although surveillance technology is currently not seen as a satisfactory alternative to restraint use, nursing staff recognises the other possibilities the technology offers in the care of residents with dementia, for example as a way to offer them more freedom or to make the current situation safer.

\section{ACKNOWLEDGEMENTS}

The study was funded by The Netherlands Organisation for Health Research and Development (ZonMw), The Hague, Netherlands.

Conflict of interest: None declared.

Funding: The study was funded by The Netherlands Organisation for Health Research and Development (ZonMw), The Hague, Netherlands.

Ethical approval: The Medical Ethics Review Committee of the VU University Medical Center approved the study protocol.

\section{REFERENCES}

ATLAS Ti, 2008 ATLAS.Ti Version 5.2, 2008. Scientific Software Development GmbH, Berlin..

Austin et al., 2005 W. Austin, G. Lemermeyer, L. Goldberg, V. Bergum and M.S. Johnson, Moral distress in healthcare practice: the situation of nurses. HEC Forum, 171 (2005), pp. 33-48.

Bloor et al., 2001 M. Bloor, J. Frankland, M. Thomas and K. Robson, Focus Groups in Social Research, SAGE Publications Ltd, London (2001).

Braun and Clarke, 2011 V. Braun and V. Clarke, Using thematic analysis in psychology. Qual. Res.

Psychol., 32 (2011), pp. 77-101.

Capezuti et al., 2007 E. Capezuti, L.M. Wagner, B.L. Brush, M. Boltz, S. Renz and K.A. Talerico, Consequences of an intervention to reduce restrictive side rail use in nursing homes. J. Am. Geriatr. Soc., 55 (2007), pp. 334-341.

Chuang and Huang, 2007 Y.H. Chuang and H.T. Huang, Nurses' feelings and thoughts about using physical restraints on hospitalized older patients. J. Clin. Nurs., 163 (2007), pp. 486-494. Council of Europe, 1950 Council of Europe, European Convention on Human Rights, (1950). de Veer et al., 2007 A.J. de Veer, A.L. Francke, A. de Kruif and J.J. Bolle, Restraining interventions. A stock-taking amongst nurses, . Tijdschrift voor Verpleeghuisgeneeskunde, 321 (2007), pp. 7-11 (in Dutch).

Engberg et al., 2008 J. Engberg, N.G. Castle and D. McCaffrey, Physical restraint initiation in nursing homes and subsequent resident health. Gerontologist, 484 (2008), pp. 442-452.

Evans et al., 2002 D. Evans, J. Wood and L. Lambert, A review of physical restraint minimization in the acute and residential care settings. J. Adv. Nurs., 406 (2002), pp. 616-625.

Evans et al., 2003 D. Evans, J. Wood and L. Lambert, Patient injury and physical restraint devices: a systematic review. J. Adv. Nurs., 413 (2003), pp. 274-282.

General, 1948 General Assembly of the United Nations, 1948. Universal declaration of human rights.. Halfens et al., 2010 R.J.G. Halfens, J.M.M. Meijers, M.F.M.T. Du Moulin, N.C. van Nie, J.C.L. Neyens and J.M.G.A. Schols, Report on the results of the national prevalence measurement on care issues, Universiteit Maastricht, CAPHRI School for Public Health and Primary Care, Department of Health Care and Nursing Science, Maastricht (2010), pp. 81-108. 
Zwijsen, S.A., Depla, M.F.I.A., Niemeijer, A.R., Francke, A.L., Hertogh, C.M.P.M. Surveillance technology: an alternative to physical restraints? A qualitative study among professionals working in nursing homes for people with dementia. International Journal of Nursing Studies: 2012, 49(2), 212-219

Hamers and Huizing, 2005 J.P. Hamers and A.R. Huizing, Why do we use physical restraints in the elderly?. Zeitschrift für Gerontologie + Geriatrie, 381 (2005), pp. 19-25.

Health Inspectorate, 2009 Health Inspectorate, The Use of Domotics in Health Care Should Be More Careful, IGZ, Den Haag (2009), (in Dutch).

Karlsson et al., 2001 S. Karlsson, G. Bucht, S. Eriksson and P.O. Sandman, Factors relating to the use of physical restraints in geriatric care settings. J. Am. Geriatr. Soc., 4912 (2001), pp. 1722-1728.

Karlsson et al., 2000 S. Karlsson, G. Bucht, G. Rasmussen and P.O. Sandman, Restraint use in elder care: decision making among registered nurses. J. Clin. Nurs., 9 (2000), pp. 842-850.

Landau et al., 2010 R. Landau, G.K. Auslander, S. Werner, N. Shoval and J. Heinik, Families' and professional caregivers' views of using advanced technology to track people with dementia. Qual. Health Res., 203 (2010), pp. 409-419.

Lauriks et al., 2008 S. Lauriks, J.P. Osté, C.M.P.M. Hertogh and R.M. Dröes, More Quality of Life Because of Domotics, Gildeprint Drukkerijen B.V., Enschede (2008), (in Dutch).

Legemaate et al., 2007 J. Legemaate, B.J.M. Frederiks and R.P. de Roode, The Special Admission to Psychiatric Hospital Act in international perspective, . Tijdschrift voor Gezondheidsrecht, 4 (2007), pp. 268-281 (in Dutch).

Mays and Pope, 2000 N. Mays and C. Pope, Qualitative research in health care. Assessing quality in qualitative research. BMJ, 3207226 (2000), pp. 50-52.

Moore and Haralambous, $2007 \mathrm{~K}$. Moore and B. Haralambous, Barriers to reducing the use of restraints in residential elder care facilities. J. Adv. Nurs., 586 (2007), pp. 532-540.

Neufeld et al., 1999 R.R. Neufeld, L.S. Libow, W.J. Foley, J.M. Dunbar, C. Cohen and B. Breuer, Restraint reduction reduces serious injuries among nursing home residents. J. Am. Geriatr. Soc., 4710 (1999), pp. 1202-1207.

Niemeijer et al., 2010 A.R. Niemeijer, B.J.N. Frederiks, I.I. Riphagen, J. Legemaate, J. Eefsting and C.M.P.M. Hertogh, Ethical and practical concerns of surveillance technologies in residential care for people with dementia or intellectual disabilities: an overview of the literature. Int. Psychogeriatr., 4 (2010), pp. 1-14.

Patrick, $2008 \mathrm{H}$. Patrick, Autonomy, benefit and protection. How human rights can protect people with mental conditions or learning disabilities from unlawful deprivation of liberty Mental Welfare Commission for ScotlandEdinburgh (2008), pp. 1-52.

Pope et al., 2002 C. Pope, R.P. van and R. Baker, Qualitative methods in research on healthcare quality. Qual. Saf. Health Care, 112 (2002), pp. 148-152.

Weiner et al., 2003 C. Weiner, N. Tabak and R. Bergman, Use of restraints on dementia patients: an ethical dilemma of a nursing staff in Israel. JONAS. Healthc Law Ethics Regul., 54 (2003), pp. 87-93.

Whitehead, 2004 L. Whitehead, Enhancing the quality of hermeneutic research: decision trail. J. Adv. Nurs., 455 (2004), pp. 512-518.

World Health Organization, 2005 World Health Organization, Resource Book on Mental Health, Human Rights and Legislation, WHO, Geneva (2005).

Zwijsen et al., 2011 S.A. Zwijsen, M.F. Depla, A.R. Niemeijer, A.L. Francke and C.M. Hertogh, The concept of restraint in nursing home practice: a mixed-method study in nursing homes for people with dementia. Int. Psychogeriatr., (2011), pp. 1-9. 
Zwijsen, S.A., Depla, M.F.I.A., Niemeijer, A.R., Francke, A.L., Hertogh, C.M.P.M. Surveillance technology: an alternative to physical restraints? A qualitative study among professionals working in nursing homes for people with dementia. International Journal of Nursing Studies: 2012, 49(2), 212-219

Table and figure

\begin{tabular}{|c|c|c|c|c|c|c|}
\hline $\begin{array}{l}\text { Nursing } \\
\text { home no. }\end{array}$ & $\begin{array}{l}\text { Number of } \\
\text { residents }\end{array}$ & $\begin{array}{l}\text { Number of nurses } \\
\text { working in the } \\
\text { nursing home }\end{array}$ & $\begin{array}{l}\text { Interview } \\
\text { key person }\end{array}$ & $\begin{array}{l}\text { Focus group } \\
\text { (with nurses or } \\
\text { multidisciplinary team) }\end{array}$ & $\begin{array}{l}\text { Policy on } \\
\text { surveillance } \\
\text { technology }\end{array}$ & Type of surveillance technology used \\
\hline 1 & 142 & 127 & 1 Physician & 1 Nurses & Yes & $\begin{array}{l}\text { GPS, Movement Sensor, Bed Pressure } \\
\text { sensors }\end{array}$ \\
\hline 2 & 72 & 34 & $\begin{array}{l}1 \text { Physician } \\
\text { 1Manager }\end{array}$ & 1 Nurses & Yes & $\begin{array}{l}\text { Acoustic monitoring, Chips worn in } \\
\text { clothing, Inactivity sensors, Movement } \\
\text { sensors, Door sensors, Bed Pressure } \\
\text { sensors }\end{array}$ \\
\hline 3 & 103 & 83 & 1 Physician & $\begin{array}{l}1 \text { Nurses } \\
1 \text { Multidisciplinary team }\end{array}$ & No & Movement sensors \\
\hline 4 & 60 & 42 & 1 Physician & 1 Nurses & No & Movement sensors, Bed pressure sensors \\
\hline 5 & 100 & 100 & 1 Manager & 1 Nurses & No & Acoustic monitoring \\
\hline 6 & 100 & 100 & 2 Physicians & 1 Nurses & No & $\begin{array}{l}\text { Acoustic monitoring, Chips worn in } \\
\text { clothing, Movement sensors }\end{array}$ \\
\hline 7 & 120 & 55 & 1 Physician & 1 Multidisciplinary team & Yes & $\begin{array}{l}\text { Chips worn in clothing, GPS, } \\
\text { Movement sensors }\end{array}$ \\
\hline
\end{tabular}

Fig. 1. Example of a vignette used in the focus groups.

Case 1: Mrs. A, aged 86, has been living in the nursing home for several years because of vascular dementia. We know Mrs. A. as an insecure/nervous woman, with a fear of failing and also a little distrustful. She has always required a lot of validation during her stay in the nursing home. Lately Mrs. A's cognitive faculties have deteriorated considerably; her understanding is severely reduced. She doesn't understand everything anymore.

Problem: Especially during the afternoon Mrs. A. is increasingly restless; when she is by herself she starts searching. There is a risk of falling; walking is not safe any more. 